\title{
Does dehydroepiandrosterone sulfate have a role in COVID-19 prognosis and treatment?
}

\author{
Sojit Tomo ${ }^{1}$, Mithu Banerjee ${ }^{1}$, Praveen Sharma ${ }^{1}$, Mahendra Garg ${ }^{2}$ \\ ${ }^{1}$ Department of Biochemistry, All India Institute of Medical Sciences, Jodhpur, India; ${ }^{2}$ Department of Medicine, \\ All India Institute of Medical Sciences, Jodhpur, India \\ E-mail:mithu.banerjee.3@gmail.com
}

The pathophysiology of COVID comprises an exaggerated pro-inflammatory response. Hypothalamic-pituitary-adrenal (HPA) axis has a crucial role in various inflammatory conditions and modulated immunological response. Limited evidence is available regarding the incidence and the effect of HPA dysfunction in COVID-19. Although the cortisol levels have only been estimated in a few studies, the dehydroepiandrosterone sulfate (DHEAS) release from the adrenal gland has not been explored yet. In this mini review, the authors discuss the role of dehydroepiandrosterone (DHEA) and DHEAS in the acute stress response and immunological modulation. Various effects of DHEAS have been demonstrated in different diseases. The specific inhibitory effect of DHEA on interleukin 6 (IL-6) could be of paramount importance in COVID-19. Further, DHEA supplementation has already been proposed in inflammatory conditions, like rheumatoid arthritis. DHEAS levels in COVID-19 may help to understand the HPA axis dysfunction as well as the possibility of repurposing DHEA as a drug for mitigating the pro-inflammatory COVID-19.

Key words: COVID-19, hypothalamic-pituitary-adrenal axis, DHEA, DHEAS, cortisol

Acute respiratory distress syndrome (ARDS) and cytokine storm are important causes leading to mortality in COVID-19. The immune response to COVID-19 and the host stress response are modulated by the alterations of the hypothalamic-pituitary-adrenal (HPA) axis. Medium to small doses of glucocorticoids facilitates the suppression of the development of cytokine storm (Xiang et al. 2020). In a recent meta-analysis of clinical trials, a lowered 28-day all-cause mortality has been demonstrated on the administration of systemic glucocorticoids (WHO REACT Working group et al. 2020). However, SARS-CoV (2003) has been shown to suppress the cortisol stress response in the host by targeting the host adrenocorticotropic hormone (ACTH) (Pal 2020). The molecular mimicry resulting from the viral peptides structurally similar to ACTH has been proposed to have a role in adrenal insufficiency in COVID-19 (Garg et al. 2020). Currently, limited evidence is available regarding the alterations of the HPA axis in COVID-19 infection.

\section{Dehydroepiandrosterone and dehydroepi- androsterone sulfate}

Dehydroepiandrosterone (DHEA) is synthesized by zona reticularis of the adrenal cortex from 17 a-hydroxypregnenolone on ACTH stimulation (Bentley et al. 2019). This androgenic steroid is sulfated to form dehydroepiandrosterone sulfate in the adrenals and peripheral tissues (Figure 1). The enzyme sulfotransferase converts DHEA to dehydroepiandrosterone sulfate (DHEAS). DHEAS has an immunostimulatory and antiglucocorticoid effects. Since cortisol and DHEAS are secreted in coordination and have opposing effects, the ratios of both

Corresponding author: Dr. Mithu Banerjee, Additional Professor and Head, Department of Biochemistry, All India Institute of Medical Sciences, Jodhpur, India; phone: +919622277766; e-mail: mithu.banerjee.3@gmail.com. 


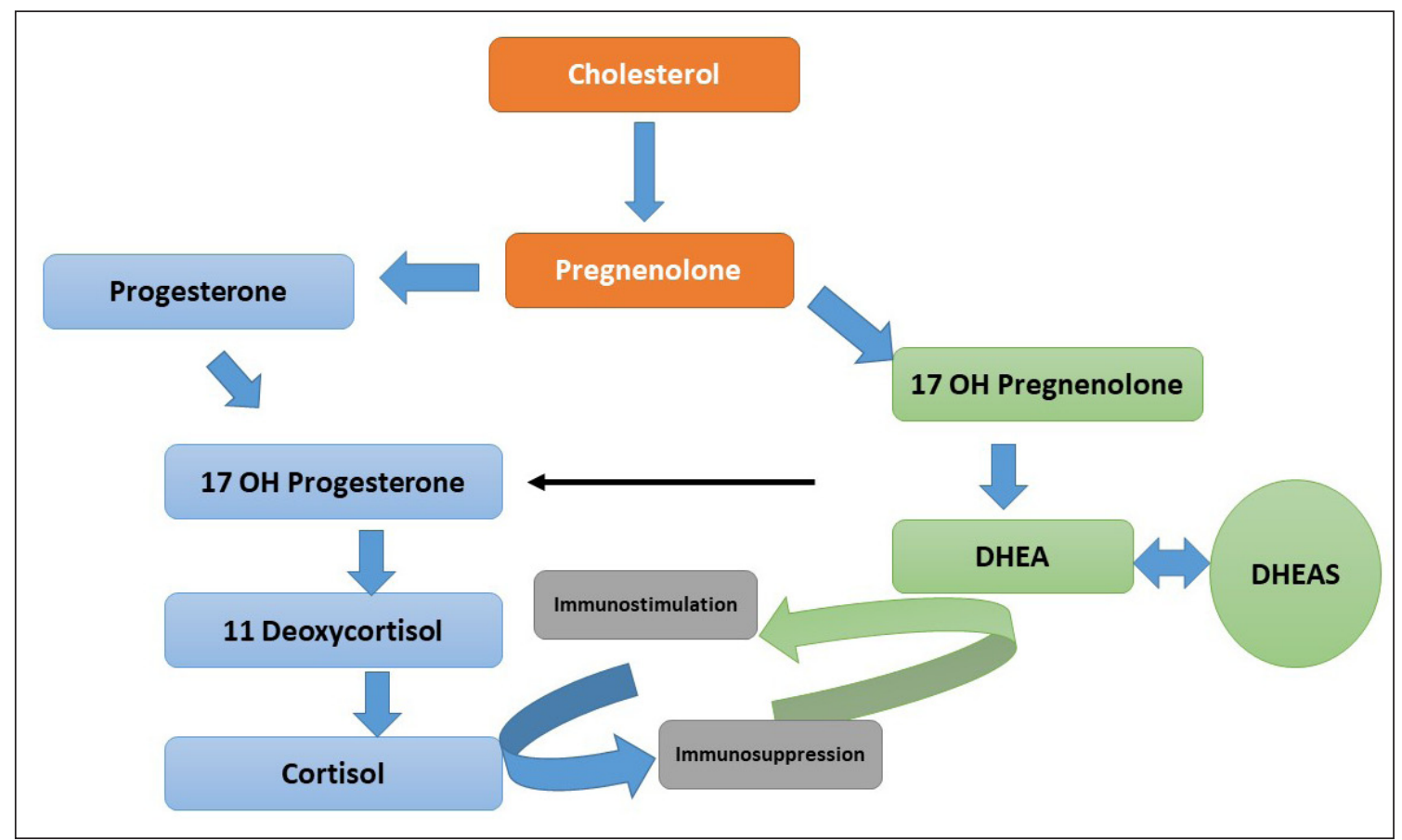

Figure 1. Schematic representation of pathway for dehydroepiandrosterone (DHEA) and dehydroepiandrosterone sulfate (DHEAS) synthesis.

have been advocated (Tsai et al. 2017). Furthermore, DHEA also acts as a precursor for other steroids, like androstenedione, testosterone, and estrogen. Normal levels of DHEA and DHEAS vary over time. Agespecific changes in the blood levels of both manifest as a decline with the progression of age (Chen and Parker 2004). The higher circulatory levels of biologically inactive DHEAS provide a consistent pool that can be converted in the endoplasmic reticulum by steroid sulfatase to DHEA (Bentley et al. 2019). The linear interconversion of DHEA to DHEAS makes it an excellent serum proxy marker for DHEA availability (Rosenfeld et al. 1972).

The alterations in blood levels of DHEA and DHEAS have been associated with a multitude of diseases. Decreased serum levels of DHEAS were associated with an increased incidence of coronary heart disease (Thijs et al. 2003). Further, a lowered DHEAS has been found to correlate with all-causes of the mortality (Phillips et al. 2010). However, polycystic ovarian disease and non-classical congenital adrenal hyperplasia are some conditions associated with elevated DHEA levels (Goodarzi et al. 2015). The decrease in DHEAS levels with the progression of age with relatively stable cortisol levels, widens the imbalance between the two hormones (Phillips et al.
2010). Suppressed levels of DHEAS and higher ratios of cortisol to DHEAS correlated with frailty in older people (Baylis et al. 2013). In addition, a multitude of inflammatory conditions, including rheumatoid arthritis, systemic lupus erythematosus, progressive systemic sclerosis, inflammatory bowel disease, have been associated with the decreased DHEAS levels (Andus et al. 1996; Straub et al. 1997).

\section{Acute stress response}

DHEAS has been shown to have an important role in inflammatory diseases and critically ill patients. A decreased DHEAS with elevated cortisol and high cortisol to DHEA ratio has been observed in severely ill patients. An extremely low level of DHEAS has been observed in patients in septic shock (Beishuizen et al. 2002). Cortisol, in critically ill patients, has been demonstrated to have a timedependent response with an initial increase in levels followed by a state of adrenal suppression initiated by the suppressed levels of ACTH by the feedback loop (Teblick et al. 2019). The cortisol to DHEA ratio has been shown to be significantly increased in nonsurvivors in patients with septic shock (Arlt et al. 2006). Low DHEAS/cortisol ratios have been corre- 
lated with the severity of inflammation. It also serves as a prognostic marker in cirrhotic patients with concurrent septic shock (Tsai et al. 2017). Further, in patients with severe sepsis, the ratio has been found to be significantly lowered in both survivors and nonsurvivors (Marx et al. 2003). Hence, in critical illness, DHEAS has been proposed as an early sign of impending exhaustion of the adrenal reserve. The cortisol/DHEAS ratio has been considered to be a predictor of long-term mortality in septic patients (De Castro et al. 2019).

Lower DHEAS has been observed in both ulcerative colitis and Crohn's disease. In Crohn's disease patients, low DHEAS, and high serum cortisol levels were associated with higher humoral inflammatory activity (Straub et al. 1998a). Patients with polymyalgia rheumatica/giant cell arteritis with new-onset active disease have also significantly lower levels of DHEAS, despite the inappropriately normal cortisol levels (Narvaez et al. 2006). Interestingly, DHEA has been found to be more sensitive to HPA axis stimulation than cortisol (Arvat et al. 2000). Contrastingly, a lower cortisol-to-DHEAS ratio with enlarged adrenal glands has been observed in fetuses exposed to intraamniotic inflammation (Buhimschi et al. 2008). This suppressed response to inflammation in fetuses has been proposed to be a part of a complex adaptive stress response modulated in anticipation of birth by premature fetuses (Buhimschi et al. 2008).

Severe acute respiratory syndrome (SARS) in SARS-associated coronavirus affects the HPA axis during the course of infection. Multiple studies have observed an elevation in cortisol levels in COVID-19 patients (Ramezani et al. 2020; Tan et al. 2020). Tan et al. (2020) have demonstrated the association between high cortisol levels and mortality. However, the prognostic role of cortisol in COVID-19 has been under debate due to the interindividual variability of cortisol secretion in response to stress, the circadian nature of its secretion, and the non-uniformity of cortisol released in response to various modes of stress (Choy 2020; Pal et al. 2020; Rajcani et al. 2020). The data regarding the association of DHEAS with HPA axis abnormality and mortality in COVID-19 is sparse. Further studies should be undertaken to assess the role of DHEAS, which has lesser variability and non-pulsatile nature, as a prognostic marker in COVID-19.

\section{Infection and immunity}

DHEA affects the immune response in the body suppressing the expression of various proinflamma- tory cy tokines (Du et al. 2001; Choi et al. 2008). DHEA has also been shown to have a specific inhibitory effect on interleukin-6 (IL-6) secretion (Marx et al. 2003). In chronic inflammation, DHEAS and DHEA have been found to be decreased and had a negative correlation with IL-6 levels (Straub et al. 2002). The suppressed levels of both DHEA and DHEAS have been associated with systemic lupus erythematosus (Suzuki et al. 1995; McMurray and May 2003).

The levels of DHEAS have been assessed in multiple infections. The DHEAS levels have been found to be decreased in human immunodeficiency virus (HIV) patients. Low CD4 T cell counts, although do not correlate with cortisol levels, exhibited a good correlation with low DHEAS levels in HIV patients (de la Torre et al. 1997). DHEAS levels were lower in hepatitis $\mathrm{C}$ virus (HCV) coinfected HIV patients (Mauboussin et al. 2004). Multiple studies have observed decreased DHEA and DHEAS in patients with tuberculosis (Santucci et al. 2011; Fernandez et al. 2020) and schistosoma infection intensity was lower in patients with high concentrations of DHEAS (Kurtis et al. 2006).

The immune-modulatory effects of DHEA lead to accentuated type $1 \mathrm{~T}$ helper (Th1) response. DHEA is a potent enhancer of interleukin-2 (IL-2) secretion from Th1 cells and negatively regulates the production of the type $2 \mathrm{~T}$ helper (Th2) cytokines IL-6 (Suzuki et al. 1991). T lymphocytes, on exposure to DHEA, have exhibited heightened cytotoxicity (Suzuki et al. 1991). In addition, DHEA directly modulates the function of the neutrophils by stimulating the synthesis of reactive oxygen species (ROS) via NADPH oxidase activation (Radford et al. 2010). Similarly, DHEA exposure lowers the activation threshold of Monocytes leading to the more effective clearing of infectious agents (McLachlan et al. 1996). Concurrently, DHEA and DHEAS have been shown to inversely correlates with serum IL-6 levels (Cutolo et al. 2002). DHEA concentration-dependent inhibition of IL-6 production from peripheral blood mononuclear cells has also been demonstrated (Straub et al. 1998b).

The excessive activation of the immune system in COVID-19 is associated with an increase of cytokines (De Biasi et al. 2020). As a result, COVID-19 has been associated with a significant increase in proinflammatory cytokines, especially IL-6 (Chen et al. 2020; Huang et al. 2020). IL-6 and C-reactive protein (CRP) effectively assessed the disease severity and predicted outcome in COVID-19 patients (Liu et al. 2020). Severe COVID-19 disease is characterized by IL-6-mediated lymphopenia and sustained 
cytokine production (Giamarellos-Bourboulis et al. 2020). COVID-19 pneumonia with ARDS, characterized by hyperinflammatory syndrome responded with significant clinical improvement to IL-6 inhibitor, Tocilizumab (Toniati et al. 2020). Tocilizumab also reduced ICU admissions and mortality in severe SARS-CoV-2 pneumonia patients (Klopfenstein et al. 2020). Patients with COVID-19 also have lower levels of regulatory $\mathrm{T}$ cells, which has been accentuated in severe cases (Qin et al. 2020). Single-cell transcriptomic analysis revealed that COVID-19 patients had a decreased number of the protective polyfunctional Th1 cells among SARS-CoV-2-reactive CD4 ${ }^{+}$ $\mathrm{T}$ cells (Meckiff et al. 2020). In addition, impaired CoV-2-specific Th1-type cellular immunity has been attributed to varying severity of the disease (Sattler et al. 2020). The potential of DHEA to blunt immunological response, suppress IL-6 levels, and increase Tregs makes is an attractive target to be explored for its therapeutic efficacy. Animal models have demonstrated that DHEA treatment can lead to decreased mRNA levels of tumor necrosis factor- $\alpha$ (TNF- $\alpha$ ), interleukin-1 $\beta$ (IL-1 $\beta$ ), IL-6, and interferon-gamma $(\mathrm{IFN}-\gamma)$ via MAPK and NF- $\kappa \mathrm{B}$ signaling pathways (Cao et al. 2020; Zhao et al. 2020).

Dexamethasone, a synthetic glucocorticoid, has been demonstrated to have effectiveness in reducing 28-day mortality in patients receiving respiratory support (RECOVERY Collaborative Group et al. 2021). However, the recent bioinformatics analysis revealed that the IL- 6 pathway is not involved in the beneficial effect of dexamethasone in COVID-19 (Sharma 2021). Similarly, computational analysis has demonstrated a more stable bond formation between dexamethasone and glucocorticoid receptor when compared with IL-6 (Fadaka et al. 2020). In addition, Ciampa et al. (2021) have demonstrated the ineffectiveness of dexamethasone in significantly altering cytokine levels. Hence, DHEA should be explored for its effectiveness in targeting the increased IL- 6 levels in COVID-19 patients, which may not be addressed by dexamethasone treatment.

\section{DHEA supplementation}

The supplementation of DHEA has already been associated with significant antiglucocorticoid and immunomodulatory actions. DHEA has antiglucocorticoid actions and has been demonstrated in numerous tissues (Browne et al. 1992; Kimonides et al. 1999; Hu et al. 2000). DHEA has a protective action against glucocorticoid-induced thymic involution and suppression of lymphocyte proliferation
(May et al. 1990; Blauer et al. 1991). Supplementation with DHEA has been shown to reverse the suppression of IL-2 synthesis by glucocorticoids (Daynes et al. 1990). DHEA supplementation has been shown to have a significant effect on the modulation of proinflammatory cytokine levels in the reduction of lupus flares (Chang et al. 2004). Oral DHEA replacement in Addison's disease leads to restoration of levels of regulatory $\mathrm{T}$ cells and the decrease in the NK cells (Coles et al. 2005). The inhibitory effect of DHEA analogs in viral multiplication has been demonstrated in influenza A virus infection where it inhibited the viral infection in the post-attachment stage (Yang et al. 2016).

Synthetic DHEA (Prasterone) therapy has been already explored in the treatment of depression and schizophrenia (Wolkowitz et al. 1997; Ritsner and Strous 2010). A synthetic analog of a metabolite of DHEA has been shown to reduce the established disease in the rodent models of rheumatoid arthritis (Offner et al. 2009). The use of synthetic analog in the mouse model also demonstrated a decrease in proinflammatory cytokines and increases in $\mathrm{T}$ reg cells (Auci et al. 2007). A daily dose of DHEA at 50 mg showed an enhanced activation of immune functions in elderly individuals with low serum DHEA levels (Khorram et al. 1997). In individuals with lower DHEAS concentrations, influenza vaccination when supplemented with a one-time dose of DHEAS showed an enhanced antibody response against the specific Hemophilus Influenza antigen (Degelau et al. 1997). The evidence from other viral diseases justifies the attempts that the therapeutic efficacy of DHEA and its analogs in COVID-19 disease may be taken into assess.

\section{Conclusion}

The assessment of DHEAS in COVID-19 patients may be explored to understand its prognostic capability with respect to severe COVID-19 disease and HPA axis abnormality in comparison to the current cortisol estimation. Besides, the repurposing of DHEA as an adjuvant therapy may be assessed for its therapeutic benefits in COVID-19 in view of its immunomodulatory properties exhibited in other autoimmune and viral diseases. However, the evolving immune landscape in COVID-19 and the emerging evidence with respect to host immune response as well as the mode of perturbations of HPA axis in COVID-19, would be crucial in evaluating the immunological benefits of DHEAS in COVID-19. 


\section{References}

Andus T, Straub RH, Vogl D et al. Low serum levels of dehydroepiandrosterone sulfate (DHEAS) in Crohn's disease (CD) and ulcerative colitis (UC). Gastroenterology 110, A855, 1996.

Arlt W, Hammer F, Sanning P, Butcher SK, Lord JM, Allolio B, Annane D, Stewart PM. Dissociation of serum dehydroepiandrosterone and dehydroepiandrosterone sulfate in septic shock. J Clin Endocrinol Metab 91, 2548-2554, 2006.

Arvat E, Di Vito L, Lanfranco F, Maccario M, Baffoni C, Rossetto R, Aimaretti G, Camanni F, Ghigo E. Stimulatory effect of adrenocorticotropin on cortisol, aldosterone, and dehydroepiandrosterone secretion in normal humans: Dose-response study. J Clin Endocrinol Metab 85, 3141-3146, 2000.

Auci D, Kaler L, Subramanian S, Huang Y, Frincke J, Reading C, Offner H. A new orally bioavailable synthetic androstene inhibits collagen-induced arthritis in the mouse: androstene hormones as regulators of regulatory T cells. Ann N Y Acad Sci 1110, 630-640, 2007.

Baylis D, Bartlett DB, Syddall HE, Ntani G, Gale CR, Cooper C, Lord JM, Sayer AA. Immune-endocrine biomarkers as predictors of frailty and mortality: a 10-year longitudinal study in community-dwelling older people. Age (Dordr) 35, 963-971, 2013.

Beishuizen A, Thijs LG, Vermes I. Decreased levels of dehydroepiandrosterone sulphate in severe critical illness: a sign of exhausted adrenal reserve? Crit Care 6, 434-438, 2002.

Bentley C, Hazeldine J, Greig C, Lord J, Foster M. Dehydroepiandrosterone: a potential therapeutic agent in the treatment and rehabilitation of the traumatically injured patient. Burns Trauma 7, 26, 2019.

Blauer KL, Poth M, Rogers WM, Bernton EW. Dehydroepiandrosterone antagonizes the suppressive effects of dexamethasone on lymphocyte proliferation. Endocrinology 129, 3174-3179, 1991.

Browne ES, Wright BE, Porter JR, Svec F. Dehydroepiandrosterone: Antiglucocorticoid action in mice. Am J Med Sci 303, 366-371, 1992.

Buhimschi CS, Turan OM, Funai EF, Azpurua H, Bahtiyar MO, Turan S, Zhao G, Dulay A, Bhandari V, Copel JA, Buhimschi IA. Fetal adrenal gland volume and cortisol/dehydroepiandrosterone sulfate ratio in inflammation-associated preterm birth. Obstet Gynecol 111, 715-722, 2008.

Cao J, Zhang H, Yang Z, Zhao J, Ma H. Effect of dehydroepiandrosterone on the immune response and gut microbiota in dextran sulfate sodium-induced colitis mice. Mol Immunol 118, 60-72, 2020.

Chang DM, Chu SJ, Chen HC, Kuo SY, Lai JH. Dehydroepiandrosterone suppresses interleukin 10 synthesis in women with systemic lupus erythematosus. Ann Rheum Dis 63, 1623-1626, 2004.

Chen CC, Parker CR Jr. Adrenal androgens and the immune system. Semin Reprod Med 22, 369-377, 2004.

Chen G, Wu D, Guo W, Cao Y, Huang D, Wang H, Wang T, Zhang X, Chen H, Yu H, Zhang X, Zhang M, Wu S, Song J, Chen T, Han M, Li S, Luo X, Zhao J, Ning Q. Clinical and immunological features of severe and moderate coronavirus disease 2019. J Clin Invest 130, 2620-2629, 2020.

Choi IS, Cui Y, Koh YA, Lee HC, Cho YB, Won YH. Effects of dehydroepiandrosterone on Th2 cytokine production in peripheral blood mononuclear cells from asthmatics. Korean J Intern Med 23, 176-181, 2008.

Choy KW. Cortisol concentrations and mortality from COVID-19. Lancet Diabetes Endocrinol 8, 808, 2020.

Ciampa ML, O’Hara TA, Joel CL, Gleaton MM, Tiwari KK, Boudreaux DM, Prasad BM. Absence of "Cytokine Storm” in hospitalized COVID-19 patients: A retrospective cohort study. Infect Dis Rep 13, 377-387, 2021.

Coles AJ, Thompson S, Cox AL, Curran S, Gurnell EM, Chatterjee VK. Dehydroepiandrosterone replacement in patients with Addison's disease has a bimodal effect on regulatory (CD4+CD25hi and CD4+FoxP3+) T cells. Eur J Immunol 35, 3694-3703, 2005.

Cutolo M, Foppiani L, Minuto F. Hypothalamic-pituitary-adrenal axis impairment in the pathogenesis of rheumatoid arthritis and polymyalgia rheumatica. J Endocrinol Invest 25, 19-23, 2002.

Daynes RA, Dudley DJ, Araneo BA. Regulation of murine lymphokine production in vivo. II. Dehydroepiandrosterone is a natural enhancer of interleukin 2 synthesis by helper T cells. Eur J Immunol 20, 793-802, 1990.

De Biasi S, Meschiari M, Gibellini L, Bellinazzi C, Borella R, Fidanza L, Gozzi L, Iannone A, Lo Tartaro D, Mattioli M, Paolini A, Menozzi M, Milic J, Franceschi G, Fantini R, Tonelli R, Sita M, Sarti M, Trenti T, Brugioni L, Cicchetti L, Facchinetti F, Pietrangelo A, Clini E, Girardis M, Guaraldi G, Mussini C, Cossarizza A. Marked T cell activation, senescence, exhaustion and skewing towards TH17 in patients with COVID-19 pneumonia. Nat Commun 11, 3434, 2020.

De Castro R, Ruiz D, Lavin BA, Lamsfus JA, Vazquez L, Montalban C, Marcano G, Sarabia R, Paz-Zulueta M, Blanco C, Santibanez M. Cortisol and adrenal androgens as independent predictors of mortality in septic patients. PLoS One 14, e0214312, 2019. 
de la Torre B, von Krogh G, Svensson M, Holmberg V. Blood cortisol and dehydroepiandrosterone sulphate (DHEAS) levels and CD4 T cell counts in HIV infection. Clin Exp Rheumatol 15, 87-90, 1997.

Degelau J, Guay D, Hallgren H. The effect of DHEAS on influenza vaccination in aging adults. J Am Geriatr Soc 45, 747-751, 1997.

Du C, Guan Q, Khalil MW, Sriram S. Stimulation of Th2 response by high doses of dehydroepiandrosterone in KLHprimed splenocytes. Exp Biol Med (Maywood) 226, 1051-1060, 2001.

Fadaka AO, Sibuyi NRS, Madiehe AM, Meyer M. Computational insight of dexamethasone against potential targets of SARS-CoV-2. J Biomol Struct Dyn 1-11, 2020.

Fernandez RDV, Diaz A, Bongiovanni B, Gallucci G, Bertola D, Gardenez W, Lioi S, Bertolin Y, Galliano R, Bay ML, Bottasso O, D’Attilio L. Evidence for a more disrupted immune-endocrine relation and cortisol immunologic influences in the context of tuberculosis and type 2 diabetes comorbidity. Front Endocrinol (Lausanne) $11,126,2020$.

Garg MK, Gopalakrishnan M, Yadav P, Misra S. Endocrine involvement in COVID-19: mechanisms, clinical features, and implications for care. Indian J Endocrinol Metab 24, 381-386, 2020.

Giamarellos-Bourboulis EJ, Netea MG, Rovina N, Akinosoglou K, Antoniadou A, Antonakos N, Damoraki G, Gkavogianni T, Adami ME, Katsaounou P, Ntaganou M, Kyriakopoulou M, Dimopoulos G, Koutsodimitropoulos I, Velissaris D, Koufargyris P, Karageorgos A, Katrini K, Lekakis V, Lupse M, Kotsaki A, Renieris G, Theodoulou D, Panou V, Koukaki E, Koulouris N, Gogos C, Koutsoukou A. Complex immune dysregulation in COVID-19 patients with severe respiratory failure. Cell Host Microbe 27, 992-1000.e3, 2020.

Goodarzi MO, Carmina E, Azziz R. DHEA, DHEAS and PCOS. J Steroid Biochem Mol Biol 145, 213-225, 2015.

$\mathrm{Hu}$ Y, Cardounel A, Gursoy E, Anderson P, Kalimi M. Anti-stress effects of dehydroepiandrosterone: Protection of rats against repeated immobilization stressinduced weight loss, glucocorticoid receptor production, and lipid peroxidation. Biochem Pharmacol 59, 753-762, 2000.

Huang C, Wang Y, Li X, Ren L, Zhao J, Hu Y, Zhang L, Fan G, Xu J, Gu X, Cheng Z, Yu T, Xia J, Wei Y, Wu W, Xie X, Yin W, Li H, Liu M, Xiao Y, Gao H, Guo L, Xie J, Wang G, Jiang R, Gao Z, Jin Q, Wang J, Cao B. Clinical features of patients infected with 2019 novel coronavirus in Wuhan, China. Lancet 395, 497-506, 2020.

Khorram O, Vu L, Yen SS. Activation of immune function by dehydroepiandrosterone (DHEA) in age-advanced men. J Gerontol A Biol Sci Med Sci 52, M1-M7, 1997.

Kimonides VG, Spillantini MG, Sofroniew MV, Fawcett JW, Herbert J. Dehydroepiandrosterone antagonizes the neurotoxic effects of corticosterone and translocation of stress-activated protein kinase 3 in hippocampal primary cultures. Neuroscience 89, 429-436, 1999.

Klopfenstein T, Zayet S, Lohse A, Balblanc JC, Badie J, Royer PY, Toko L, Mezher C, Kadiane-Oussou NJ, Bossert M, Bozgan AM, Charpentier A, Roux MF, Contreras R, Mazurier I, Dussert P, Gendrin V, Conrozier T; HNF Hospital Tocilizumab multidisciplinary team. Tocilizumab therapy reduced intensive care unit admissions and/or mortality in COVID-19 patients. Med Mal Infect 50, 397-400, 2020.

Kurtis JD, Friedman JF, Leenstra T, Langdon GC, Wu HW, Manalo DL, Su L, Jiz M, Jarilla B, Pablo AO, McGarvey ST, Olveda RM, Acosta LP. Pubertal development predicts resistance to infection and reinfection with Schistosoma japonicum. Clinical Infectious Diseases 42, 1692-1698, 2006.

Liu F, Li L, Xu M, Wu J, Luo D, Zhu Y, Li B, Song X, Zhou X. Prognostic value of interleukin-6, C-reactive protein, and procalcitonin in patients with COVID-19. J Clin Virol 127, 104370, 2020.

Marx C, Petros S, Bornstein SR, Weise M, Wendt M, Menschikowski M, Engelmann L, Hoffken G. Adrenocortical hormones in survivors and nonsurvivors of severe sepsis: diverse time course of dehydroepiandrosterone, dehydroepiandrosterone-sulfate, and cortisol. Crit Care Med 31, 1382-1388, 2003.

Mauboussin JM, Mahamat A, Peyriere H, Rouanet I, Fabbro-Peray P, Daures JP, Vincent D. Low plasma levels of dehydroepiandrosterone sulphate in HIV-positive patients coinfected with hepatitis C virus. HIV Med 5, 151-157, 2004.

May M, Holmes E, Rogers W, Poth M. Protection from glucocorticoid induced thyme involution by dehydroepiandrosterone. Life Sciences 46, 1601-1609, 1990.

McLachlan JA, Serkin CD, Bakouche O. Dehydroepiandrosterone modulation of lipopolysaccharide stimulated monocyte cytotoxicity. J Immunol 156, 328-335, 1996.

McMurray RW, May W. Sex hormones and systemic lupus erythematosus: review and meta-analysis. Arthritis Rheum 48, 2100-2110, 2003.

Meckiff BJ, Ramirez-Suastegui C, Fajardo V, Chee SJ, Kusnadi A, Simon H, Eschweiler S, Grifoni A, Pelosi E, Weiskopf D, Sette A, Ay F, Seumois G, Ottensmeier CH, Vijayanand P. Imbalance of regulatory and cytotoxic SARS-CoV-2-reactive CD4+ T cells in COVID-19. Cell 183, 1340-1353.e16, 2020. 
Narvaez J, Bernad B, Diaz Torne C, Momplet JV, Montpel JZ, Nolla JM, Valverde-Garcia J. Low serum levels of DHEAS in untreated polymyalgia rheumatica/giant cell arteritis. J Rheumatol 33, 1293-1298, 2006.

Offner H, Firestein GS, Boyle DL, Pieters R, Frincke JM, Garsd A, White SK, Reading CL, Auci DL. An orally bioavailable synthetic analog of an active dehydroepiandrosterone metabolite reduces established disease in rodent models of rheumatoid arthritis. J Pharmacol Exp Ther 329, 1100-1109, 2009.

Pal R. COVID-19, hypothalamo-pituitary-adrenal axis and clinical implications. Endocrine 68, 251-252, 2020.

Pal R, Banerjee M, Bhadada SK. Cortisol concentrations and mortality from COVID-19. Lancet Diabetes Endocrinol 8, 809, 2020.

Phillips AC, Carroll D, Gale CR, Lord JM, Arlt W, Batty GD. Cortisol, DHEA sulphate, their ratio, and all-cause and cause-specific mortality in the Vietnam Experience Study. Eur J Endocrinol 163, 285-292, 2010.

Qin C, Zhou L, Hu Z, Zhang S, Yang S, Tao Y, Xie C, Ma K, Shang K, Wang W, Tian DS. Dysregulation of immune response in patients with coronavirus 2019 (COVID-19) in Wuhan, China. Clin Infect Dis 71, 762-768, 2020.

Radford DJ, Wang K, McNelis JC, Taylor AE, Hechenberger G, Hofmann J, Chahal H, Arlt W, Lord JM. Dehydroepiandrosterone sulfate directly activates protein kinase C-beta to increase human neutrophil superoxide generation. Mol Endocrinol 24, 813-821, 2010.

Rajcani J, Solarikova P, Brezina I, Jezova D. Neuroendocrine responses to a psychosocial stress test for larger groups of participants: comparison of two test exposures. Endocr Regul 54, 255-259, 2020.

Ramezani M, Simani L, Karimialavijeh E, Rezaei O, Hajiesmaeili M, Pakdaman H. The role of anxiety and cortisol in outcomes of patients with Covid-19. Basic Clin Neurosci 11, 179-184, 2020.

RECOVERY Collaborative Group, Horby P, Lim WS, Emberson JR, Mafham M, Bell JL, Linsell L, Staplin N, Brightling C, Ustianowski A, Elmahi E, Prudon B, Green C, Felton T, Chadwick D, Rege K, Fegan C, Chappell LC, Faust SN, Jaki T, Jeffery K, Montgomery A, Rowan K, Juszczak E, Baillie JK, Haynes R, Landray MJ. Dexamethasone in hospitalized patients with Covid-19. N Engl J Med 384, 693-704, 2021.

Ritsner MS, Strous RD. Neurocognitive deficits in schizophrenia are associated with alterations in blood levels of neurosteroids: a multiple regression analysis of findings from a double-blind, randomized, placebo-controlled, crossover trial with DHEA. J Psychiatr Res 44, 75-80, 2010.

Rosenfeld RS, Hellman L, Gallagher TF. Metabolism and interconversion of dehydroisoandrosterone and dehydroisoandrosterone sulfate. J Clin Endocrinol Metab 35, 187-193, 1972.

Santucci N, D’Attilio L, Kovalevski L, Bozza V, Besedovsky H, del Rey A, Bay ML, Bottasso O. A multifaceted analysis of immune-endocrine-metabolic alterations in patients with pulmonary tuberculosis. PLoS One 6, e26363, 2011.

Sattler A, Angermair S, Stockmann H, Heim KM, Khadzhynov D, Treskatsch S, Halleck F, Kreis ME, Kotsch K. SARS-CoV-2-specific T cell responses and correlations with COVID-19 patient predisposition. J Clin Invest $130,6477-6489,2020$

Sharma A. Inferring molecular mechanisms of dexamethasone therapy in severe COVID-19 from existing transcriptomic data. Gene 788, 145665, 2021.

Straub RH, Antoniou E, Zeuner M, Lock G, Scholmerich J, Lang B. High prolactin and low dehydroepiandrosterone sulfate serum levels in patients with severe systemic sclerosis. Br J Rheumatol 36, 426-432, 1997.

Straub RH, Vogl D, Gross V, Lang B, Scholmerich J, Andus T. Association of humoral markers of inflammation and dehydroepiandrosterone sulfate or cortisol serum levels in patients with chronic inflammatory bowel disease. Am J Gastroenterol 93, 2197-2202, 1998a.

Straub RH, Konecna L, Hrach S, Rothe G, Kreutz M, Scholmerich J, Falk W, Lang B. Serum dehydroepiandrosterone (DHEA) and DHEA sulfate are negatively correlated with serum interleukin-6 (IL-6), and DHEA inhibits IL-6 secretion from mononuclear cells in man in vitro: possible link between endocrinosenescence and immunosenescence. J Clin Endocrinol Metab 83, 2012-2017, 1998b.

Straub RH, Lehle K, Herfarth H, Weber M, Falk W, Preuner J, Scholmerich J. Dehydroepiandrosterone in relation to other adrenal hormones during an acute inflammatory stressful disease state compared with chronic inflammatory disease: role of interleukin-6 and tumour necrosis factor. Eur J Endocrinol 146, 365-374, 2002.

Suzuki T, Suzuki N, Daynes RA, Engleman EG. Dehydroepiandrosterone enhances IL-2 production and cytotoxic effector function of human T cells. Clin Immunol Immunopathol 61, 202-211, 1991.

Suzuki T, Suzuki N, Engleman EG, Mizushima Y, Sakane T. Low serum levels of dehydroepiandrosterone may cause deficient IL-2 production by lymphocytes in patients with systemic lupus erythematosus (SLE). Clin Exp Immunol 99, 251-255, 1995.

Tan T, Khoo B, Mills EG, Phylactou M, Patel B, Eng PC, Thurston L, Muzi B, Meeran K, Prevost AT, Comninos AN, Abbara A, Dhillo WS. Association between high serum total cortisol concentrations and mortality from COVID-19. Lancet Diabetes Endocrinol 8, 659-660, 2020. 
Teblick A, Peeters B, Langouche L, Van den Berghe G. Adrenal function and dysfunction in critically ill patients. Nat Rev Endocrinol 15, 417-427, 2019.

Thijs L, Fagard R, Forette F, Nawrot T, Staessen JA. Are low dehydroepiandrosterone sulphate levels predictive for cardiovascular diseases? A review of prospective and retrospective studies. Acta Cardiol 58, 403-10, 2003.

Toniati P, Piva S, Cattalini M, Garrafa E, Regola F, Castelli F, Franceschini F, Airò P, Bazzani C, Beindorf EA, Berlendis M, Bezzi M, Bossini N, Castellano M, Cattaneo S, Cavazzana I, Contessi GB, Crippa M, Delbarba A, De Peri E, Faletti A, Filippini M, Filippini M, Frassi M, Gaggiotti M, Gorla R, Lanspa M, Lorenzotti S, Marino R, Maroldi R, Metra M, Matteelli A, Modina D, Moioli G, Montani G, Muiesan ML, Odolini S, Peli E, Pesenti S, Pezzoli MC, Pirola I, Pozzi A, Proto A, Rasulo FA, Renisi G, Ricci C, Rizzoni D, Romanelli G, Rossi M, Salvetti M, Scolari F, Signorini L, Taglietti M, Tomasoni G, Tomasoni LR, Turla F, Valsecchi A, Zani D, Zuccalà F, Zunica F, Focà E, Andreoli L, Latronico N. Tocilizumab for the treatment of severe COVID-19 pneumonia with hyperinflammatory syndrome and acute respiratory failure: A single center study of 100 patients in Brescia, Italy. Autoimmun Rev 19, 102568, 2020.

Tsai MH, Huang HC, Peng YS, Chen YC, Tian YC, Yang CW, Lien JM, Fang JT, Wu CS, Hsieh SY, Lee FY. Dehydroepiandrosterone sulfate and dehydroepiandrosterone sulfate/cortisol ratio in cirrhotic patients with septic shock: another sign of hepatoadrenal syndrome? Crit Care 21, 214, 2017.

WHO Rapid Evidence Appraisal for COVID-19 Therapies (REACT) Working Group, Sterne JAC, Murthy S, Diaz JV, Slutsky AS, Villar J, Angus DC, Annane D, Azevedo LCP, Berwanger O, Cavalcanti AB, Dequin PF, Du B, Emberson J, Fisher D, Giraudeau B, Gordon AC, Granholm A, Green C, Haynes R, Heming N, Higgins JPT, Horby P, Jüni P, Landray MJ, Le Gouge A, Leclerc M, Lim WS, Machado FR, McArthur C, Meziani F, Møller MH, Perner A, Petersen MW, Savovic J, Tomazini B, Veiga VC, Webb S, Marshall JC. Association Between Administration of Systemic Corticosteroids and Mortality Among Critically Ill Patients With COVID-19: A Meta-analysis. JAMA 324, 1330-1341, 2020.

Wolkowitz OM, Reus VI, Roberts E, Manfredi F, Chan T, Raum WJ, Ormiston S, Johnson R, Canick J, Brizendine L, Weingartner H. Dehydroepiandrosterone (DHEA) treatment of depression. Biol Psychiatry 41, 311-318, 1997.

Xiang Z, Liu J, Shi D, Chen W, Li J, Yan R, Bi Y, Hu W, Zhu Z, Yu Y, Yang Z. Glucocorticoids improve severe or critical COVID-19 by activating ACE2 and reducing IL-6 levels. Int J Biol Sci 16, 2382-2391, 2020.

Yang Q, Mao Q, Liu M, Wang K, Wu Z, Fang W, Yang Z, Luo P, Ke S, Shi L. The inhibitory effect of dehydroepiandrosterone and its derivatives against influenza A virus in vitro and in vivo. Arch Virol 161, 3061-3072, 2016.

Zhao J, Cao J, Yu L, Ma H. Dehydroepiandrosterone resisted E. Coli O157:H7-induced inflammation via blocking the activation of p38 MAPK and NF-кB pathways in mice. Cytokine 127, 154955, 2020. 